\title{
O NEGÓCIO DA FALSA CIÊNCIA E O AMPLO ACESSO AO CONHECIMENTO CIENTÍFICO
}

Exatamente há um ano, a Revista de Direito Sanitário discutiu aqui, nesta seção, as questões da independência do pesquisador em relação à edição científica e da justificação moral do direito de propriedade intelectual percebido pelas casas editoras das revistas científicas. Na ocasião, foram lembradas as inciativas, tanto nos Estados Unidos quanto na Europa, em favor do acesso aberto (open access) aos trabalhos publicados nas revistas científicas editadas por grupos privados. Verificou-se, contudo, que as grandes plataformas - que agregam vastos campos científicos e que vêm servindo como base para a avalição da produtividade dos pesquisadores - nasceram como programas "pagantes" e permanecem incompatíveis com a lógica de "processos abertos". Assim, depois de analisar os principais entraves tanto ao acesso aberto quanto ao open process, indispensáveis à ciência aberta, foi reafirmada a conclusão de cientistas franceses segundo os quais a superação de "todos esses desafios exige um reforço de cooperação internacional das entidades públicas confrontadas às mesmas tendências e comungando as mesmas prioridades"1.

Agora, uma pesquisa internacional realizada por um grupo de jornalistas reunidos no projeto Fake Science examinou uma base de dados com 175 mil artigos e apresentações em conferências "duvidosas" e publicou seus resultados em veículos de imprensa respeitáveis (entre eles o francês Le Monde, o norueguês Aftenposten, os alemães Süd-deutsche Zeitung e Norddeutsche Rundfunk, entre outros). Esses resultados são estarrecedores. Existe um negócio muito bem orquestrado que vem se aproveitando da injunção posta aos pesquisadores de publicar muito. Ele funciona assim: as sociedades que publicam revistas "duvidosas" ou organizam falsas conferências científicas escrevem para pesquisadores e empresas de todo o mundo e recomendam uma publicação em determinado periódico científico. Em seguida, elas publicam - mediante pagamento rapidamente as contribuições dos pesquisadores, muitas vezes sem o adequado exame do conteúdo. Desse modo, mesmo estudos “duvidosos" vêm à luz com um selo de "ciência”.

E o fenômeno não é exclusivo de uma região do planeta. A mesma pesquisa mostrou que o número dessas publicações "predadoras" triplicou nos últimos cinco anos no mundo inteiro, envolvendo cerca de 400 mil pesquisadores. Na Alemanha, por exemplo, um dos principais membros do Conselho Nacional de Ciência e o reitor da Universidade de Bremen publicaram nessas revistas ${ }^{2}$. Na França, cerca de 50 artigos

\footnotetext{
${ }^{1}$ CNRS - Direction de l'Information Scientifique et Technique. L'Edition de sciences à l'heure numérique: dynamiques en cours (2015). p. 8. Disponível em: <http://www.cnrs.fr/dist/z-outils/documents/Distinfo2/Distetude2.pdf>. ${ }^{2}$ TAUSENDE Forscher publizieren in Pseudo-Journalen. Süddeutsche Zeitung, 19 Juli 2018. Disponível em: <https:// www.sueddeutsche.de/wissen/wissenschaft-tausende-forscher-publizieren-in-pseudo-journalen-1.4061005>.
} 
foram publicados em 2015 nessas revistas "duvidosas" pelo montante de 46 mil euros, informou a ministra do Ensino Superior, da Pesquisa e da Inovação, Frédérique Vidal ${ }^{3}$.

A Índia aparece como um dos maiores mercados para o negócio das revistas "duvidosas", envolvendo mais de 300 editoras que publicam mais de seis mil revistas. Instaladas em um escritório central luxuoso ou em uma sala com apenas uma pessoa e um computador, essas publicações, em sua maioria, existem on-line, dizem ter uma lista de especialistas como editores e realizam pouca ou nenhuma checagem antes da publicação ${ }^{4}$. É justo notar, porém, que apenas uma pequena parte da clientela dessas editoras "predadoras" sediadas na Índia vem de fato da Índia.

E a França parece ser a capital mundial das ciências, tal o número de conferências científicas ali realizadas. Essas "paródias" de conferência científica são organizadas por empresas que amortizam seus custos com dois ou três participantes que paguem as taxas de inscrição. Aqui também vale notar que nem todos os pesquisadores que se inscrevem nesse tipo de conferência são vítimas, pois muitos veem nelas uma oportunidade de viajar às expensas de sua instituição, às vezes sem perceber que estão desviando dinheiro público.

A "gangrena da falsa ciência", como foi denominada em editorial do jornal Le Monde, vem se alimentando principalmente de dois fenômenos. Por um lado, a pressão para publicar e apresentar artigos em conferências internacionais como meio de pontuar nos processos de recrutamento ou promoção dos sistemas acadêmicos e de pesquisas vem incentivando o negócio da falsa ciência, ameaçando não apenas a reputação pessoal de cientistas, mas também a confiança na própria ciência. Por outro, a luta contra o monopólio dos grandes editores científicos e pelo livre acesso aos resultados das pesquisas acabou introduzindo o princípio do pagamento para a publicação do artigo, em geral feito pela instituição à qual o pesquisador está vinculado, como condição para cobrir as despesas de publicação e assegurar o acesso livre de custos a todos os interessados. Os editores dessas publicações pseudocientíficas souberam tirar partido de tais mudanças no ambiente científico. Elas são encontradas nos catálogos de bibliotecas universitárias, bem como em teses de mestrado e doutorado, e são citadas por autoridades nacionais e internacionais.

Assegurar o amplo acesso ao conhecimento científico deve ser, portanto, uma preocupação política, uma questão de interesse nacional. É preciso readequar os sistemas de avaliação de pesquisas, valorizando mais a qualidade do que

${ }^{3}$ FOUCART, S.; LAROUSSERIE, D. Impostures scientifiques. Le Monde, 20 Juil. 2018. p. 6-7.

${ }^{4}$ YADAV, Shyamlal. Inside India's fake research paper shops: pay, publish, profit. The Indian Express, 19 July 2018. Disponivel em: <https://indianexpress.com/article/india/inside-indias-fake-research-paper-shopspay-publish-profit-5265402/>. 
a quantidade. Mas é necessário também um engajamento para que "os resultados da pesquisa científica sejam abertos a todos, pesquisadores, empresas e cidadãos, sem entraves, sem demora, sem pagamento"s. E, aqui, talvez o caso francês possa servir de exemplo. Já lembramos que, em outubro de 2015, a promulgação da Lei n. 2016-1321 assegurou o livre acesso às publicações científicas fruto de pesquisa pública, por meio do direito de os pesquisadores divulgarem seus artigos após um embargo de seis a 12 meses, independentemente do contrato assinado com os editores das revistas, e tornou livre a reutilização de dados de pesquisa (art. 30, que incluiu o artigo L-533-4, incisos I a IV, no Código da Pesquisa [criado pela Ordonnance n. 2004-545, de 11 de junho de 2004]). Agora, em julho de 2018, em uma conferência anual da Liga das Bibliotecas Europeias de Pesquisa (Liber) ${ }^{6}$, foi anunciado o plano francês para uma ciência aberta, contendo três eixos orientadores: (i) generalizar a abertura das publicações, tornando obrigatória a difusão em acesso aberto dos artigos e obras originados de pesquisas financiadas por verbas públicas, criando um fundo para a ciência aberta a fim de contribuir para o reinvestimento no controle do sistema editorial pela comunidade científica; (ii) estruturar e, tanto quanto possível, abrir os dados das pesquisas, tornando obrigatória a difusão em acesso aberto dos dados originados de pesquisas financiadas por verbas pública, criando a função de administrador de dados junto ao Ministério da Educação Superior, da Pesquisa e da Inovação e estimulando a associação dos dados estruturados e abertos aos artigos publicados pelos pesquisadores; e (iii) fazer da França o país da ciência aberta, transformando as práticas científicas para integrar a ciência aberta no cotidiano, estimulando as universidades e os organismos de pesquisa a adotarem uma política de ciência aberta, combinando a questão das publicações, dos dados, das competências e da avaliação e articulando as ações nacionais em nível europeu e internacional.

Trata-se de um enorme desafio, cujo enfrentamento é urgente tanto para o círculo mais fechado dos pesquisadores, que não querem ser confundidos com falsos profetas, quanto para todo o povo, que precisa do conhecimento produzido com competência e seriedade para fundamentar suas decisões a respeito dos riscos a assumir em nome da vida em sociedade. Nossa Revista de Direito Sanitário é editada pelo Núcleo de Pesquisa em Direito Sanitário da Universidade de São Paulo (NAP-DISA/USP) e pelo Centro de Estudos e Pesquisas de Direito Sanitário (Cepedisa) e o acesso a todos os artigos publicados é livre e imediato. Queremos, além disso, nos engajar em um programa nacional que faça também do Brasil um país da ciência aberta. E, como vimos, a ciência aberta apenas será construída quando pesquisadores,

${ }^{5}$ PLAN national pour la science ouverte: discours de Frédérique Vidal. Ministère de l'Enseignement supérieur, de la Recherche et de l'Innovation. Disponível em: <http://www.enseignementsup-recherche.gouv.fr/ cid132531/plan-national-pour-la-science-ouverte-discours-de-frederique-vidal.html>.

${ }^{6}$ RESEARCH Libraries Powering Sustainable Knowledge in the Digital Age. LIBER Europe Strategy, 2018-2022. Disponivel em: <https://libereurope.eu/wp-content/uploads/2017/11/LIBERStrategy-2018-2022.pdf>. 
empresas, organizações de pacientes, professores, alunos, agricultores e cidadãos em geral puderem participar do processo. Insistimos, portanto, para que enviem seus artigos, resenhas ou comentários sobre trabalho forense, ou ainda suas sugestões de temas para debate e nomes de eventuais debatedores. Não deixem de contribuir!

Sueli Gandolfi Dallari

Editora Científica 